\title{
Recovery of Ionic Liquid from Aqueous Phase Pyrolytic Oil: A Simulation Using ASPEN HYSYS V10 ${ }^{\circledR}$
}

\author{
Isah Yakub Mohammed*1, Yousif Abdalla Abakr², Hyelni Gana Mshelia ${ }^{3}$ and Shafihi Umar ${ }^{4}$ \\ ${ }^{1}$ Department of Chemical Engineering, Abubakar Tafawa Balewa University, P.M.B 0248 Bauchi, Nigeria \\ ${ }^{2}$ Department of Mechanical, Materials and Manufacturing Engineering, University of Nottingham, Jalan Broga, \\ Semenyih 43500, Selangor Darul Eshan, Malaysia \\ ${ }^{3}$ Standards Organisation of Nigeria No 52 Lome crescent Wuse zone 7 Abuja, Nigeria \\ ${ }^{4}$ Department of Chemical Engineering, Federal polytechnic, PMB 55, Bida, Niger State, Nigeria.
}

*Corresponding author E-mail: yimohd@atbu.edu.ng

Received 6 March 2021

Accepted for publication 4 April 2021

Published 11 May 2021

\begin{abstract}
Aqueous phase pyrolytic oil is generally considered less important and often discarded as a pyrolysis by-product due to lack of specific applications. Although, recent studies have proposed production of hydrogen via catalytic aqueous and steam reforming from this stream, however, these processes require complex system. Imidazole is one of the major components of aqueous phase pyrolytic oil which can be converted into different products. This study presents a new valorisation strategy of aqueous phase pyrolytic oil into renewable ionic liquid through simulation. A steady state process simulation for recovery of imidazole from aqueous phase pyrolytic oil and subsequent conversion into ionic liquid was developed using ASPEN HYSYS V10 ${ }^{\circledR}$. Effects of different operating variables such as feed flow rate, composition and temperature on the imidazole recovery, ionic liquid yield and composition were investigated. The simulation results revealed that high yield of renewable ionic liquid with physicochemical properties comparable to that of commercially available ionic liquids can be produced from aqueous phase pyrolytic oil. This product can be utilised for biomass refining since ionic liquid have been reported to selectively remove hemicellulose and lignin in many biomass related applications such as pre-treatment and characterization.
\end{abstract}

Keywords: Pyrolytic oil; Aqueous phase; chemical intermediate; imidazole; Ionic liquid; SDG7 


\section{Introduction}

Bioenergy systems offer significant possibilities for reducing greenhouse gas emissions due to their immense potential to replace fossil-based fuels in energy production [1]. Lignocellulosic biomass from non-food crops cultivated on lands that are increasingly marginal for more favoured major crops are potential source of sustainable renewable energy. Napier grass is one of the underutilised energy crops with high biomass yield and low establishment cost. It requires little or no nutrient input with typical biomass yield of 25-35 oven dry tonnes/hectare [2], making it one of the most promising bioenergy feedstock. Biomass conversion via thermochemical process such as pyrolysis represent a sustainable approach towards reducing the reliance on fossil fuels as it can handle any biomass feedstock and capable of producing high liquid yield [3]. Valorisation of Napier grass into pyrolytic oil has been reported in the literature. The results from these studies showed the yield of pyrolytic oil typically in the range of 35-60 $\mathrm{wt} \%$ depending on the type of pyrolysis process, reactor type and process variables used [3-5]. Generally, pyrolytic oil is produced in two phases, organic phase and aqueous phase. The organic phase contains water-insoluble high molecular weight components and represent the most valuable precursor for the production of liquid biofuel. The aqueous phase (low molecular weight component) on the other hand, constitutes the light fractions predominantly water (originates from both moisture in the feed biomass and pyrolysis reaction), acids, ketones, aldehydes, imidazole-based chemicals, small fraction of phenols and other water-soluble organics. This stream is generally considered less important and often discarded as pyrolysis by-products due to lack of specific applications. Recent studies have proposed production of hydrogen via catalytic aqueous, and steam reforming processes from this stream [6]. However, these processes require complex system, which calls for further studies to understand the reaction mechanisms [7].

Ionic liquids generally composed of ions that are fluid at relatively low temperature, from ambient temperature to $100{ }^{\circ} \mathrm{C}$. They are also known as green solvents owing to their unique characteristics as they produced non-toxic or non-explosive gases when used [8]. These properties make them potential substitute to the conventional volatile solvents that are believed to result in photochemical smog, ozone depletion and global climate change. There has been considerable interest in ionic liquid for the processing of lignocellulosic biomass derived from a variety of sources (woods, grasses, energy crop, agro-residues) over the last decade due to their ability to dissolve lignocellulosic biomass and its constituents thereby tackling the key challenges of reducing biomass recalcitrance and therefore facilitate the utilisation of biomass for the production of specific bio-based products [9]. Imidazolium ionic liquids have been the most popular for experimental investigations of lignocellulosic biomass treatments, which contain 1-ethyl3-methylimidazolium or [EMIM], 1-allyl-3-methylimidazolium or [AMIM] and 1-butyl-3methylimidazolium or [BMIM] cations $[10,11]$. Synthesis of ionic liquids such as 1-Butyl-3methylimidazolium Chloride, [bmim] $\mathrm{Cl}$ has been reported in the literature. According to Welton [12], synthesis of 1-Butyl-3-methylimidazolium Chloride, [bmim]Cl start with a vigorous mixing of solution of 1-methylimidazole $(1.25 \mathrm{~mol})$ in toluene $\left(125 \mathrm{~cm}^{3}\right)$ at $0{ }^{\circ} \mathrm{C}$ followed by addition of 1 -chlorobutane $(144$ $\mathrm{cm} 3,1.38 \mathrm{~mol})$. Thereafter, the mixture is heated to reflux at $110{ }^{\circ} \mathrm{C}$ for 24 hours, after which it is placed in a freezer at about $-20 \mathrm{oC}$ for 12 hours. The toluene is decanted and the remaining viscous oil/semi-solid re-crystallized from acetonitrile and then repeated re-crystallized from ethylacetate to yield a white crystalline solid, which is dried in a vacuum to give [bmim $] \mathrm{Cl}(\mathrm{C} 8 \mathrm{H} 15 \mathrm{ClN} 2)$. However, the current 
approach for the synthesis of ionic liquids follows the wet chemistry method, which involves 1methylimidazole obtained from non-renewable source. Furthermore, the cost of ionic liquid is one of the main impediments to its utilisation in a biorefinery. It requires high level of investment and therefore lacks competitiveness relative to other solvents for biomass refining. Application of process modelling and simulation for synthesis of ionic liquid becomes very important in order to ascertain the process performance so as to determine the most suitable pathway. The objective of this study is to develop a novel process route for recovery of renewable ionic liquid intermediate from aqueous phase pyrolytic oil using ASPEN HYSYS ${ }^{\circledR}$.

\section{Materials and Method}

The composition of aqueous phase pyrolytic oil used was obtained from the literature as reported by Mohammed et al. [13]. The oil was produced at $600{ }^{\circ} \mathrm{C}$ from Napier grass (bone dried, $2.5 \mathrm{~mm}$ particle size) in a vertical fixed bed pyrolysis system. Aqueous phase pyrolytic oil was recovered using centrifuge and the chemical composition was determined using a gas chromatograph-mass spectrometer (GC-MS) system (PerkinElmer Clarus ${ }^{\circledR}$ SQ 8, Akron, USA) with a quadruple detector and PerkinElmer-EliteTM$5 \mathrm{~ms}$ column $(30 \mathrm{~m} \times 0.25 \mathrm{~mm} \times 0.25 \mu \mathrm{m})$ (PerkinElmer, Akron, USA). The oven was programmed at an initial temperature of $40{ }^{\circ} \mathrm{C}$, ramp at $5{ }^{\circ} \mathrm{C} / \mathrm{min}$ to $280{ }^{\circ} \mathrm{C}$ and held there for $20 \mathrm{~min}$. The injection temperature, volume, and split ratio were $250{ }^{\circ} \mathrm{C}, 1 \mu \mathrm{L}$, and 50:1 respectively. Helium was used as a carrier gas at a flow rate of $1 \mathrm{~mL} / \mathrm{min}$. MS ion source at $250{ }^{\circ} \mathrm{C}$ with $70 \mathrm{eV}$ ionization energy was used. Peaks of the chromatogram were identified by comparing with standard spectra of compounds in the National Institute of Standards and Technology (NIST, Gaithersburg, MD, USA) library. Summary of the list of chemical composition is presented in Table 1. The process simulation was developed using ASPEN HYSYS V10 ${ }^{\circledR}$ as summarised in the flow chart (Figure 1).

Table 1 : List of chemical compounds in Aqueous phase pyrolytic identified using GC-MS

\begin{tabular}{|c|c|c|}
\hline Chemical compounds & Formula & Mass fraction \\
\hline 1,2,4,5-cyclohexanetetrol, (1.alpha.,2.alpha.,4.alpha.,5.beta.)- & $\mathrm{C}_{6} \mathrm{H}_{12} \mathrm{O}_{4}$ & 0.0120 \\
\hline carbonic acid, 2,2,2-trichloroethyl cyclohexylmethyl ester & $\mathrm{C}_{10} \mathrm{H}_{15} \mathrm{O}_{3} \mathrm{Cl}_{3}$ & 0.0320 \\
\hline z,z-6,28-heptatriactontadien-2-one & $\mathrm{C}_{37} \mathrm{H}_{70} \mathrm{O}$ & 0.0241 \\
\hline cyclohexene, 3,5-dimethyl- & $\mathrm{C}_{8} \mathrm{H}_{14}$ & 0.0158 \\
\hline but-3-en-1-yl 2-methylbutanoate & $\mathrm{C}_{9} \mathrm{H}_{16} \mathrm{O}_{2}$ & 0.0143 \\
\hline undecanoic acid, 11-mercapto- & $\mathrm{C}_{11} \mathrm{H}_{22} \mathrm{O}_{2} \mathrm{~S}$ & 0.0149 \\
\hline phosphonic acid, (P-hydroxyphenyl)- & $\mathrm{C}_{6} \mathrm{H}_{7} \mathrm{O}_{4} \mathrm{P}$ & 0.0231 \\
\hline furan, tetrahydro-2,5-dimethoxy- & $\mathrm{C}_{6} \mathrm{H}_{12} \mathrm{O}_{3}$ & 0.0102 \\
\hline 2-ethyl-5-propylcyclopentanone & $\mathrm{C}_{10} \mathrm{H}_{18} \mathrm{O}$ & 0.0189 \\
\hline imidazole, 2-aminocarbonyl-1-methyl- & $\mathrm{C}_{5} \mathrm{H}_{7} \mathrm{ON}_{3}$ & 0.0264 \\
\hline 1,3,5-cycloheptatriene, 1-methoxy- & $\mathrm{C}_{8} \mathrm{H}_{10} \mathrm{O}$ & 0.0156 \\
\hline 2-propenamide, N-(4-aminobutyl)-3-(3,4-dihydroxyphenyl)-, (E)- & $\mathrm{C}_{13} \mathrm{H}_{18} \mathrm{O}_{3} \mathrm{~N}_{2}$ & 0.0414 \\
\hline benzene, (ethenyloxy)- & $\mathrm{C}_{8} \mathrm{H}_{8} \mathrm{O}$ & 0.0196 \\
\hline 1,2-benzenediol, 3-methoxy- & $\mathrm{C}_{7} \mathrm{H}_{8} \mathrm{O}_{3}$ & 0.0219 \\
\hline phenol, 2,6-dimethoxy- & $\mathrm{C}_{8} \mathrm{H}_{10} \mathrm{O}_{3}$ & 0.0338 \\
\hline phenol, 4-methoxy-3-(methoxymethyl)- & $\mathrm{C}_{9} \mathrm{H}_{12} \mathrm{O}_{3}$ & 0.0125 \\
\hline benzene, 1,2,3-trimethoxy-5-methyl- & $\mathrm{C}_{10} \mathrm{H}_{14} \mathrm{O}_{3}$ & 0.0079 \\
\hline 2-propanone, 1-(4-hydroxy-3-methoxyphenyl)- & $\mathrm{C}_{10} \mathrm{H}_{12} \mathrm{O}_{3}$ & 0.0093 \\
\hline phenol, 2,6-dimethoxy-4-(2-propenyl)- & $\mathrm{C}_{11} \mathrm{H}_{14} \mathrm{O}_{3}$ & 0.0075 \\
\hline
\end{tabular}

3 https://doi.org/10.47959/AJET.2021.1.1.2

(C) 2021 The Authors. Published by SRF. This is an open access article under the CC BY license (http://creativecommons.org/licenses/by/4.0/). 


\section{Pyrolytic oil components}
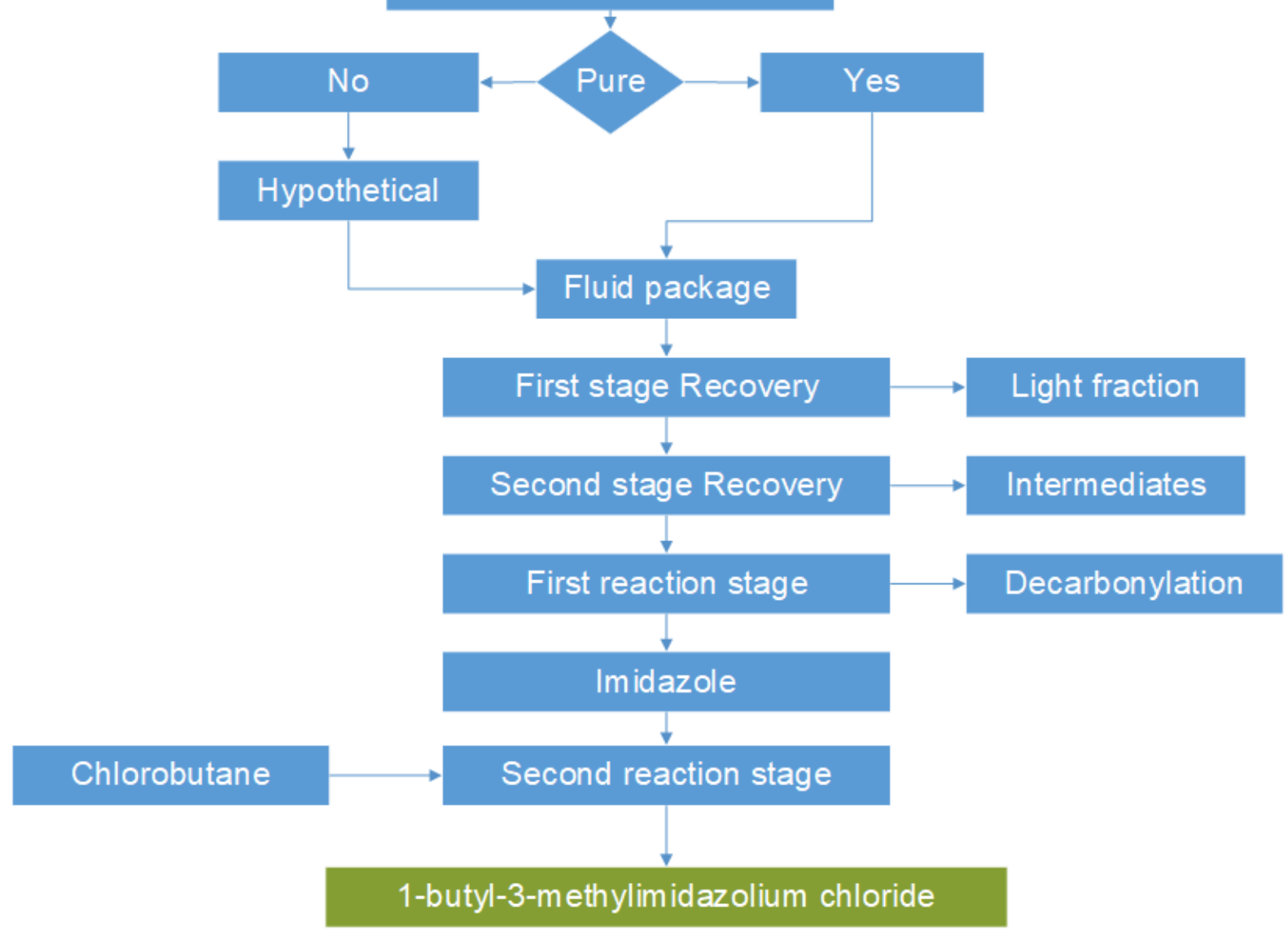

Figure 1: Process flow chart for the production ionic liquid from aqueous phase pyrolytic oil

\section{Results and Discussion}

The process flow diagram was developed using the modified Peng-Robinson equation of state (PRSV), which allows the extension of original Peng-Robinson method for highly non-ideal systems. This fluid package is capable of performing rigorous calculations for aqueous systems containing water, methanol or glycols, as well as systems containing other hydrocarbons or non-hydrocarbons in the liquid phase. This characteristic informed its choice for the simulation of the aqueous phase pyrolytic oil. Figure 2 below shows the steady state of the process flow. It consists of two split units (X-100 and X-101), two reaction vessels (V-100 and V-102), a separator (V101), mixer (MIX-100) and cooler (E-100). These units were selected based on the procedure for ionic liquid synthesis reported in the literature. The split units were used to represent reduced pressure systems, which allows selective recovery of chemical species of interest from mixtures. In this study, the water present in the pyrolytic oil constitute approximately $63 \%$ (Table 1) and about $77 \%$ of it was recovered from the feed stream into the bottom product (B1). In the top stream (F1) from the X-100, about $15 \%$ imidazole-based compound (imidazole, 2-aminocarbonyl-1-methyl-) was recovered. This was further improved to $82 \%$ in the top stream (ILF) from X-101. In the V-100 
reactor, imidazole, 2-aminocarbonyl-1-methyl- undergoes thermal decarbonylation reaction to produce methyl-imidazole with carbon monoxide as the main by-product. Effect of heat flow (Qrxt) which is a function of the vessel temperature was evaluated. From Figure 3, increase in the heat flow from $1000 \mathrm{~kJ} / \mathrm{h}$ increased the production of methyl-imidazole, which became optimum (63 wt\%) at $3000 \mathrm{~kJ} / \mathrm{hr}$ with corresponding reaction temperature of about $250{ }^{\circ} \mathrm{C}$. This suggests that highest thermal decarbonylation of 1-methyl-1H-imidazole-2-carboxamide ( $95 \%$ conversion) into methyl-imidazole is around $250{ }^{\circ} \mathrm{C}$, any further increase in the heat flow or temperature beyond this point will have no impact on the yield of the methyl-imidazole.

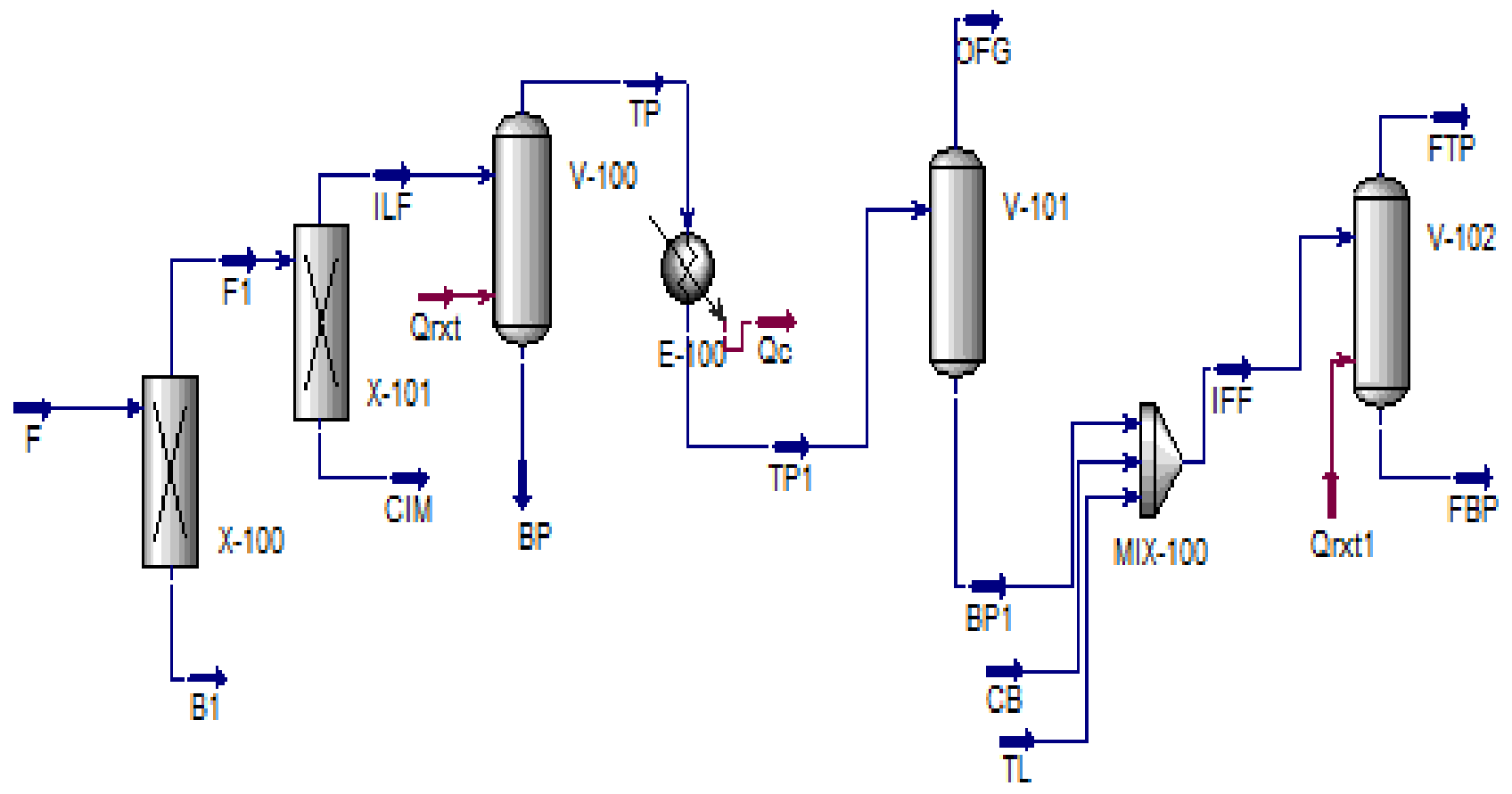

Figure 2: Process flow diagram for the production ionic liquid from aqueous phase pyrolytic oil using ASPEN HYSYS® 


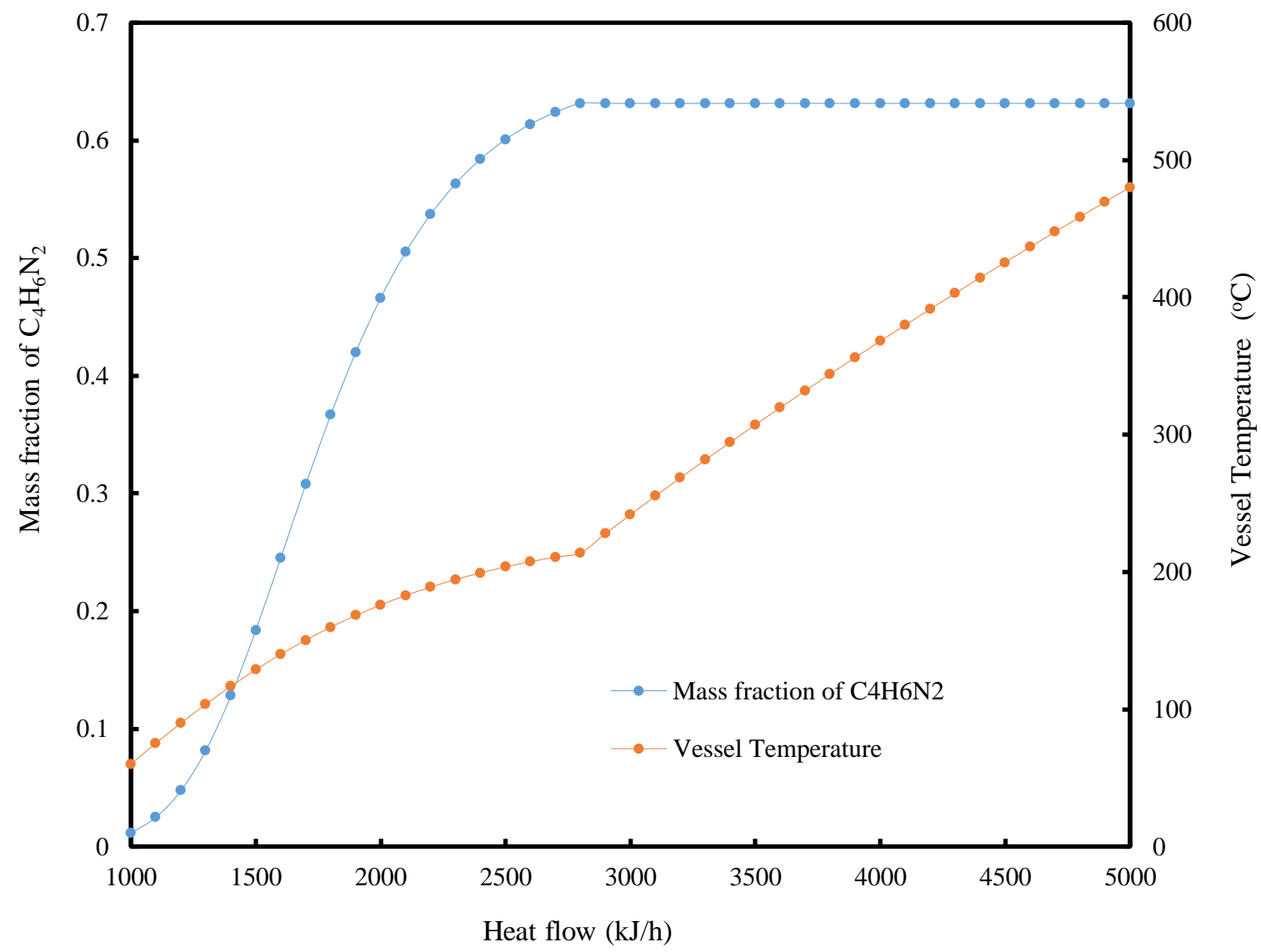

Figure 3: Effect of temperature on the decarbonylation reaction of imidazole, 2-aminocarbonyl-1-methyl- into methylimidazole

The methyl-imidazole rich stream (TP) was quenched in the E100 to around $38{ }^{\circ} \mathrm{C}$. The cold stream TP1 was charged into V101 to remove the gaseous product (OFG). The bottom BP1 was mixed with chlorobutane in toluene according to the synthesis protocol outlined in the literature and thereafter the mixture (IFF) was charged into V102 reactor. Figure 4 shows the effect of heat flow/reaction temperature on the product (ionic liquid) mass flow rate and composition. Increasing the heat flow up to $2000 \mathrm{~kJ} / \mathrm{h}$ only produced $22 \mathrm{wt} \%$ ionic liquid (1-Butyl-3-methylimidazolium Chloride) in the flow bottom product (FBP), which corresponds to around $85{ }^{\circ} \mathrm{C}$ reaction temperature. Under this condition, the mass flow rate of the ionic liquid product was steady, approximately $3 \mathrm{~kg} / \mathrm{h}$ in the FBP. With further increase in the heat/reaction temperature, the mass flow decreased starting from reaction temperature around $94{ }^{\circ} \mathrm{C}(4000 \mathrm{~kJ} / \mathrm{h})$ while the composition started increasing. This trend could be attributed to the increasing reaction temperature, which may have led to vaporisation of the feedstock needed for the production of ionic liquid. The mass flow of ionic liquid in the product stream decreased rapidly while the opposite trend was observed for the composition, which attained maximum $(84 \mathrm{wt} \%)$ at reaction temperature of $166^{\circ} \mathrm{C}$. This is $25 \mathrm{wt} \%$ higher than the reaction condition $\left(110^{\circ} \mathrm{C}\right)$ specified in the literature in addition to high purity level as more than $90 \%$ recovery of excess chlorobutane and nearly non-presence of unreacted methyl-imidazole. 


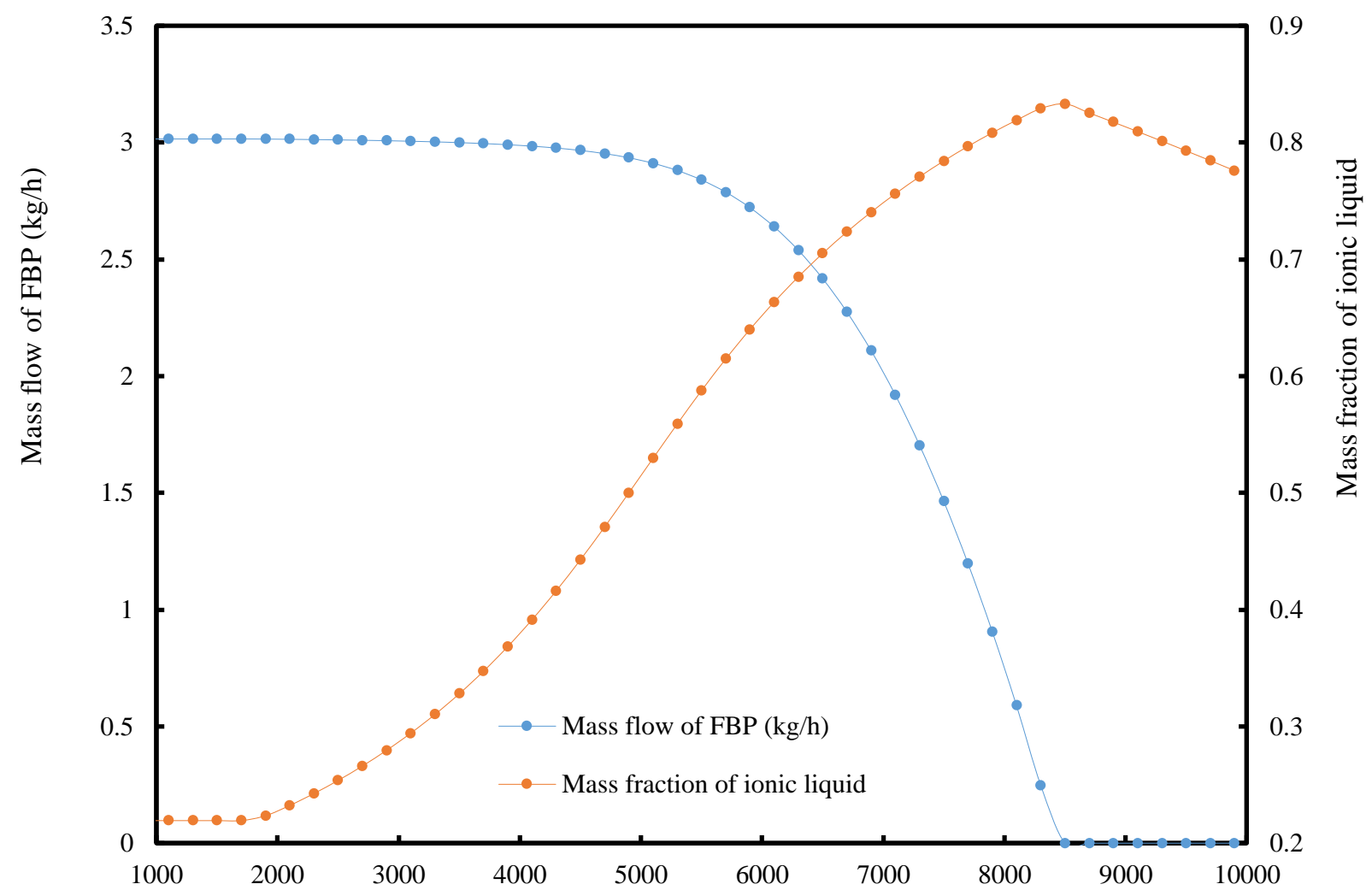

Heat flow $(\mathrm{kJ} / \mathrm{h})$

Figure 4: Effect of heat flow/ temperature on the conversion of methyl-imidazole into ionic liquid. FBP: flow bottom product

Selection of ionic liquid as a solvent for specific application requires full understanding of its properties such as molecular weight, viscosity, surface tension, heat capacity, and thermal conductivity among others. Effect of process variable on the physicochemical properties of the ionic liquid was evaluated. In this study, Figure 5 shows the variation of the viscosity and molecular weight of the ionic liquid product with respect to the heat/reaction temperature. Increasing reaction temperature initially reduced the viscosity of the FBP but later increased with the increasing temperature and became maximum $(0.4 \mathrm{cP})$ at $112^{\circ} \mathrm{C}(5500 \mathrm{~kJ} / \mathrm{h})$. This suggest that there is increase in the intermolecular van der Waals interactions in the 1-butyl-3-methylimidazolium chloride with temperature, which is a typical characteristics of a cation ionic liquid [14]. Generally, viscosity of ionic liquids is temperature dependent and according to Wilkes [14], it varies over a range of $<10$ to $>1000 \mathrm{cP}$ at room temperature. On the other hand, the molecular weight of the FBP increased continuously with temperature and attain optimum (174) at $166{ }^{\circ} \mathrm{C}$. This value is similar to the value (174.67) quoted in the Merck ${ }^{\circledR}$ material safety data (MSDS) for the 1-Butyl3-methylimidazolium chloride. 


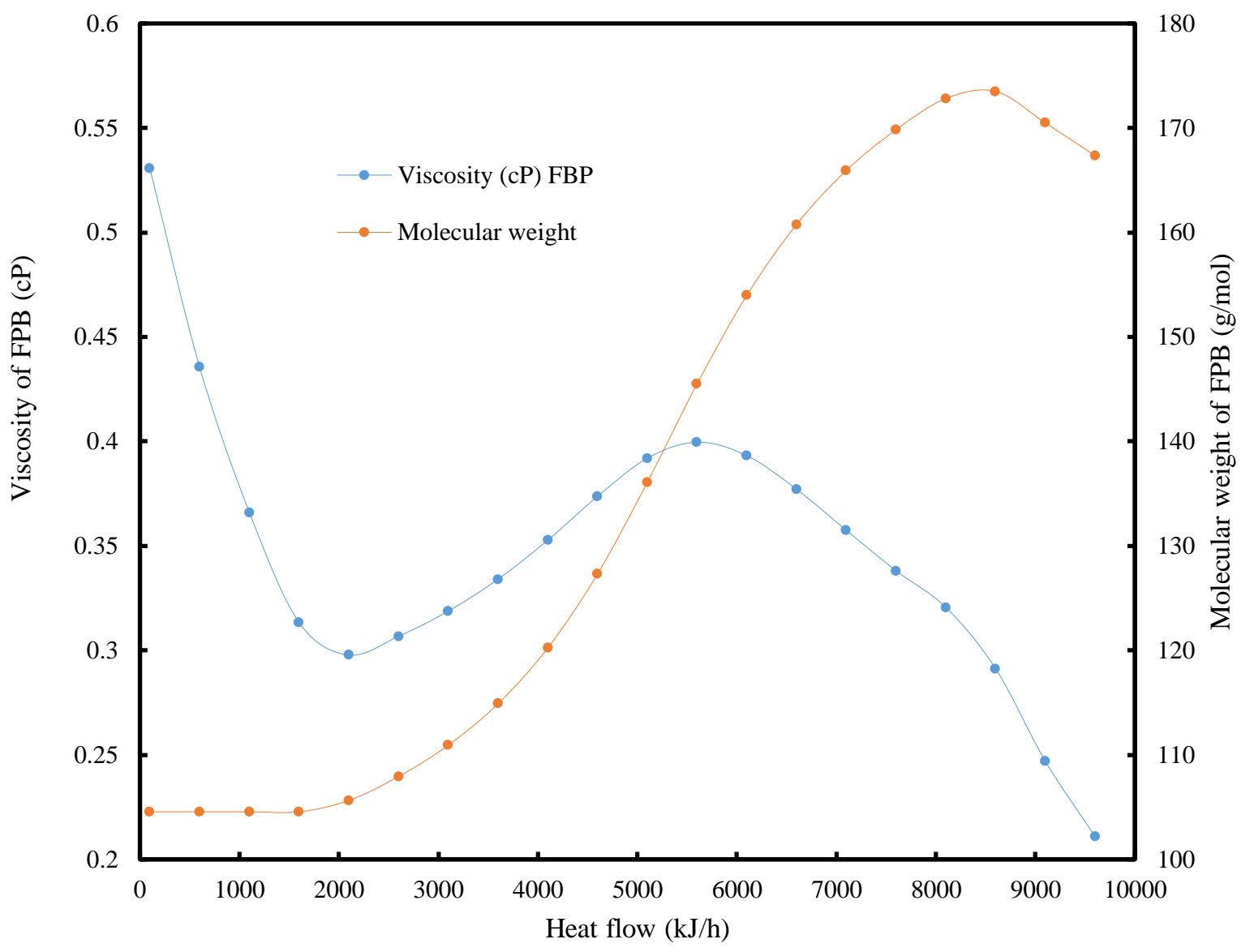

Figure 5: Effect of heat flow on the viscosity and molecular weight of 1-Butyl-3-methylimidazolium chloride

The heat capacity is very important in the Engineering systems particularly when large production systems are required. Literature has shown that the heat capacity of many imidazole-based ionic liquids is in the range of $1.281-1.659 \mathrm{~J} / \mathrm{g} .{ }^{\circ} \mathrm{C}$ [15]. From Figure 6 below, this property increased with increasing heat flow from 100 to $2000 \mathrm{~kJ} / \mathrm{h}$ and became approximately steady from 2000 to $5500 \mathrm{~kJ} / \mathrm{h}$ with corresponding value of $2.30 \mathrm{~J} / \mathrm{g} .{ }^{\circ} \mathrm{C}$. While the thermal conductivity displayed an opposite trend with a value of 0.10 $\mathrm{W} / \mathrm{m} . \mathrm{K}$ at $5500 \mathrm{~kJ} / \mathrm{h}\left(112^{\circ} \mathrm{C}\right)$. The value of thermal conductivity reported in the literature for some ionic liquids is in the range of $0.131-0.20 \mathrm{~W} / \mathrm{m} / \mathrm{K}$ [15]. 


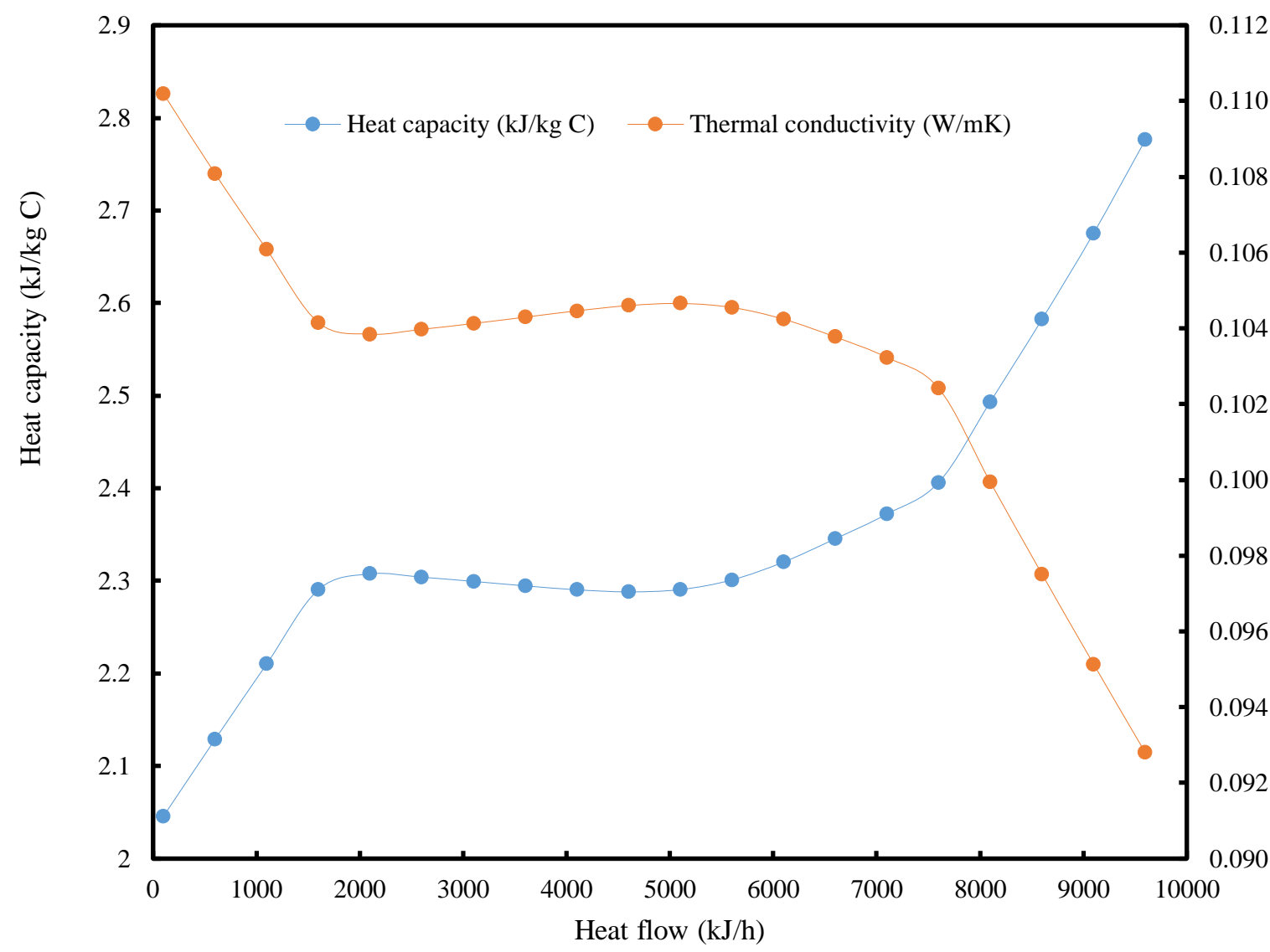

Figure 6: Effect of heat flow on the heat capacity and thermal conductivity of 1-Butyl-3-methylimidazolium chloride

\section{Conclusion}

Aqueous phase pyrolytic oil is one of the nearly zero value products from the pyrolysis process due to lack of specific applications. This study has developed a new pathway for recovery of imidazole from aqueous phase pyrolytic and subsequent conversion into valuable green solvent, the renewable ionic liquid using steady state simulation with ASPEN HYSYS ${ }^{\circledR}$. The simulation results show that high yield of renewable ionic liquid with physicochemical properties equivalent to that of commercially available nonrenewable ionic liquids. This suggests that production of renewable ionic liquid from biomass pyrolysis process would improve the carbon neutrality of the process and eventually reduce the cost of biomass refining since ionic liquid is utilised in different stages of biomass refining such as pre-treatment, fractionation and characterization. The results presented in this study may serve as a guide for synthesis of ionic liquid with specific required properties. 


\section{References}

[1] Dafaalla, A., Saeed, M. K., Badri, S., \& Alhaj, M. (2021). Sustainable development and the role of African scientific research centres. African Journal of Engineering \& Technology.DOI: 10.47959/ajet.2021.1.1.1

[2] Mohammed, I. Y., Abakr, Y. A., Kazi, F. K., Yusup, S., Alshareef, I., \& Chin, S. A. (2015). Comprehensive characterization of napier grass as a feedstock for thermochemical conversion. Energies, 8(5), 3403-3417. https://doi.org/10.3390/en8053403

[3] Mohammed, I.Y., Abakr, Y.A., Yusup, S., Kazi, F.K. 2017a. Valorization of Napier grass via intermediate pyrolysis: Optimization using response surface methodology and pyrolysis products characterization. Journal of Cleaner Production, 142, 1848-1866. https:doi.org/10.1016/j.jclepro.2016.11.099

[4] Strezov V, Evans TJ, Hayman C. 2008. Thermal conversion of elephant grass (Pennisetum purpureum Schum) to bio-gas, bio-oil and charcoal. Bioresource Technology, 99(17), 8394-8399 https://doi.org/10.1016/j.biortech.2008.02.039

[5] Lee M-K, Tsai W-T, Tsaic Y-L, Lin S-H. 2010. Pyrolysis of Napier grass in an inductionheatingreactor. J Anal Appl Pyrolysis 88, 110-116 https://doi.org/10.1016/j.jaap.2010.03.003.

[6] Resende, F.L.P., 2016. Recent advances on fast hydropyrolysis of biomass, Catalysis Today, 269, 148-155 https://doi.org/10.1016/j.cattod.2016.01.004.

[7] Mohammed, I.Y. 2017, Pyrolysis of Napier grass to bio-oil and catalytic upgrading to high grade bio-fuel. Doctoral dissertation, University of Nottingham http://eprints.nottingham.ac.uk/39572/1

[8] Yoo, C.G., Pu, Y., Ragauskas, A.J., 2017, Ionic liquids: Promising green solvents for lignocellulosic biomass utilization, Current Opinion in Green and Sustainable Chemistry, 5, 5-11. https://doi.org/10.1016/j.cogsc.2017.03.003

[9] Li, H. Y., Chen, X., Li, Y. J., Cao, X. F., Sun, S. N., \& Sun, R. C. 2018. The effect of ionic liquids pretreatment on the distribution and structure of alkali-soluble hemicelluloses from Eucalyptus. $\begin{array}{llll}\text { Separation } \quad \text { and } & \text { Purification }\end{array}$ https://doi.org/10.1016/j.seppur.2017.08.058

[10] Carneiro, A.P., Rodriguez, O., Macedo, E.A., 2017, Dissolution and fractionation of nut shells in ionic liquids. Bioresour Technol, 227, 188-196. https://doi.org/10.1021/ie302896n

[11] Kassaye, S., Pant, K.K., Jain, S. 2017, Hydrolysis of cellulosic bamboo biomass into reducing sugars via a combined alkaline solution and ionic liquid pretreament steps, Renewable Energy, 104, 177-184. https://doi.org/10.1016/j.renene.2016.12.033

[12] Welton, T., 1999. Room-temperature ionic liquids. Solvents for synthesis and catalysis. Chemical reviews, 99(8), 2071-2084. https://doi.org/10.1021/cr980032t

[13] Mohammed, I.Y., Abakr, Y.A., Hui, J.N.X., Alaba, P.A., Morris, K.I., Ibrahim, M.D. 2017b, Recovery of clean energy precursors from Bambara groundnut waste via pyrolysis: Kinetics, products distribution and optimisation using response surface methodology, Journal of Cleaner Production, 164, 1430-1445. https://doi.org/10.1016/j.jclepro.2017.07.068

[14] Dharaskar, S. A., Varma, M. N., Shende, D. Z., Yoo, C. K., Wasewar, K. L., 2013, Synthesis, characterization and application of 1-butyl-3 methylimidazolium chloride as green material for extractive desulfurization of liquid fuel, The Scientific World Journal, 2013, 1-9. https://doi.org/10.1155/2013/395274

[15] Wilkes, J. S., 2004, Properties of ionic liquid solvents for catalysis. Journal of Molecular Catalysis 
A: Chemical, 214(1), 11-17 https://doi.org/10.1016/j.molcata.2003.11.029. 